\title{
Comparison on the Antioxidant Activities of Extracts from Six Tropical Fruit Tree Leaves \\ Liqing $\mathrm{Du}^{\mathrm{a}}$,Feiyue $\mathrm{Ma}^{\mathrm{b}}$, ' Qiong $\mathrm{Fu}^{\mathrm{c}}$, Yuge Liu ${ }^{\mathrm{d}}$, Xiumei Zhang ${ }^{\mathrm{e},}$
}

\author{
Key Laboratory of Tropical Fruit Biology, Ministry of Agriculture, South Subtropical Crop \\ Research Institute, Chinese Academy of Tropical Agricultural Science (CATAS), Zhanjiang \\ 524091, Guangdong, China \\ a duliqing927618@163.com, b mfyflc@yahoo.com, ${ }^{\mathrm{c}}$ bingqi1986@163.com, ${ }^{\mathrm{d}}$ liuyugehb@126.com, ${ }^{\mathrm{e}}$ \\ asiazhang1975@163.com \\ ${ }^{*}$ correspondence
}

Keywords: Leaf; Phenolic compounds; Antioxidant activity

Abstract: Phenolic acids concentrations, total phenolic and flavonoid contents and antioxidant activities in extracts from Naseberry, Jackfruit,Longan, Litchi, Carambola and Loquat leaves were determined. The total phenolic contents varied from $4.43 \%$ in Litchi to $11.97 \%$ in Naseberrys. The Four major phenolics, rutin, ellagic acid, chlorogenic acid and salicylic acid were by HPLC (high performance liquid chromatography) analysis. Rutin was the most abundant phenolic in Jackfruit (up to $445.45 \mathrm{ug} / \mathrm{g} \mathrm{DW}$ ) and Litchi (up to $304.44 \mathrm{ug} / \mathrm{g} \mathrm{DW}$ ), whereas ellagic acid was the dominant phenolic in Naseberry (about $363 \mathrm{ug} / \mathrm{g}$ DW). The methanol extracts of these fruit leaves had strong free radical scavenging capability, metal chealting capacity and reducing power. In general, the six leaves are good sources of natural antioxidants and could be used as natural antioxidant ingredients.

\section{Introduction}

Most plant extracts and their components have been reported to exhibit biological activities, especially antimicrobial, antifungal[1], antibacterial, anticancer and antioxidant activities [2]. These compounds are widely present in various medicinal plant organs such as stems, roots, leaves, barks, flowers, fruits and seeds. Most of them are alkaloids, tannins, flavonoids and phenolic acids [3].

The study of antioxidant substances in food and natural sources has recently gained increased interest. Thus, they can increase the antioxidant intake in the diet and be used as natural antioxidant sources in food additives. Our previous study indicated that six plants leaves, such Naseberry, Jackfruit, Loquat, Longan, Litchi and Carambola have significant antioxidants (data unpublished). In this study we focused the six medicinal plants growing in Zhanjiang regions of Guangdong. The informations of their potential biological effects and antioxidant activity of leaves has not been documented. Thus, the main aim of this study was to identify the phytochemicals and evaluate possible antioxidant activities of selected plants.

\section{Materials and methods}

\subsection{Materials and reagents}

The leaves were collected from the National Germplasm Repository of South Subtropical Crops Research Institute (SSCRI) in Zhanjiang, China.

Chemical standards were obtained from Sigma Aldrich (Guangzhou, China). DPPH (2,2-Diphenyl-1-picrylhydrazyl), trolox (2,5,7,8-tetramethylchroman-2-carboxylic acid), TPTZ (2,4,6-tripyridyl-s-triazine), PMS(phenazine mentosulphate), NADH (nicotineamide adenine dinucleotide), Folin-ciocalteau reagent, HPLC grade methanol and acetonitrile were from Sigma Aldrich(Guangzhou, China). Other analytical grade reagents were purchased from Sinopharm Chemical Reagent Co., Ltd., (Shanghai, China).

\subsection{Preparation of samples}

After each leaves sample was ground, 10 grams of ground samples were weighted and mixed with $60 \mathrm{~mL}$ of $75 \%$ methanol. The extraction was repeated twice with sonication for 60 min at room temperature using an ultrasonic water bath $(40 \mathrm{kHz})$. After centrifuged for $10 \mathrm{~min}$, the methanol 
layers were combined and evaporated to dryness at $40^{\circ} \mathrm{C}$ in a rotary evaporator (Heidolph Hei-VAP Precision, German). The dried extracts were used to the compositions and antioxidant activities analysis.

\subsection{Analysis of Phenolic Compounds by HPLC.}

Phenolic compounds were determined by reversed phase HPLC (LC-20A, Shimadzu,Japan) coupled with $\mathrm{C}_{18}(250 \times 4.6 \mathrm{~mm}, 5 \mu$,Phenomenex,USA) and a diode array detector. The mobile phase consisted of acetonitrile (solvent A) and water with $1 \%$ acetic acid (solvent B). The conditions of the HPLC methods for phytochemicals were as same as in the study of $\mathrm{Du}^{[4]}$.

\subsection{Determination of total phenolics (TP) and total flavonoids (TF) contents}

The determination method of total phenolics content was described in the study of Jang \& Xu ${ }^{[5]}$. The absorbance was measured by a UV-Vis double beam spectrometer (1600 Shimadzu, Kyoto, Japan) at $750 \mathrm{~nm}$.

Total flavonoids content was determined based on the method in a previous study ${ }^{[6]}$. The absorbance of the solution was measured at $506 \mathrm{~nm}$.

\subsection{Assay of antioxidant capacity}

The DPPH assay was performed according to the study of Liyana-Pathirana and Shahidi ${ }^{[7]}$ with minor modification. The method of ABTS assay was based on the procedure described in the study of Re et al ${ }^{[8]}$. The procedure of FRAP method was based on the method developed by Benzie and Strain $^{[9]}$. The metal chelating capacity (MCC) was determined by the method of Dinis, Madeira and Almeida ${ }^{[10]}$.

\section{Results and discussion}

\subsection{Contents of total phenolics and flavonoids}

Table 1.The total phenolics and flavonoids contents in each extract of different samples (Mean \pm SD)

\begin{tabular}{ccccccc}
\hline Content[\%] & Jackfruit & Naseberry & Litchi & Longan & Carambola & Loquat \\
\hline TP & $6.63 \pm 0.43$ & $11.97 \pm 0.11$ & $4.43 \pm 0.28$ & $4.95 \pm 0.15$ & $5.57 \pm 0.29$ & $5.29 \pm 0.09$ \\
TF & $18.25 \pm 0.74$ & $11.51 \pm 0.12$ & $10.68 \pm 0.59$ & $10.82 \pm 1.23$ & $16.17 \pm 3.21$ & $11.60 \pm 0.54$ \\
\hline
\end{tabular}

The total phenolics contents of the extracts were measured using the Folin-Ciocalteu method, which relied on the transfer of electrons from phenolic compounds to the Folin-Ciocalteu reagent in alkaline medium. Phenolics compounds such as phenolic acids, flavonoids and tannins were considered to be the major contributors to the antioxidant activities of plant extracts. As showed in Table 1, total phenolics contents had variation among the different samples ranging from 4.43 to $11.97 \%$. Naseberry had the highest TP content (11.97\%), followed by Jackfruit $(6.63 \%)$, Carambola (5.57\%) and Longan (4.95\%), which Litchi had the lowest TP content $(4.43 \%)$.

The total flavonoid contents of the leaves extracts differed significantly, and varied from 10.68 to $18.25 \%$. TF content of Jackfruit was the highest, while it was the lowest for Litchi.

\subsection{The profile of bioactive compounds}

Phenolic acids occur in different forms, such as aglycones (free phenolic acids), esters, glycosides, and/or bound complexes. In this study free phenolic acids in different extracts were determined (Table 2). Among twenty-one identified phenolics, rutin, ellagic acid, chlorogenic acid and salicylic acid were the predominant phenolics. As showed in Table 2, Litchi and Jackfruit had more than ten phenolics and the highest concentration of rutin at 304.4 and $445.45 \mathrm{ug} / \mathrm{g}$, respectively), followed by salicylic acid $(218.6 \mathrm{ug} / \mathrm{g})$, ellagic acid $(178.2 \mathrm{ug} / \mathrm{g})$ and epicatechin $86.45 \mathrm{ug} / \mathrm{g}$ ) in the Litchi leaves. Chlorogenic acid contraction was the second and $122.28 \mathrm{ug} / \mathrm{g} \mathrm{DW}$ in Jckfruit leaves. Ellagic acid and chlorogenic acid were identified as the predominant phenolic acids in Nseberry, Chlorogenic acid was the only predominant phenolic acid in Loquat, while the predominant one was ellagic acid in Longan and myricetin in Carambola.

The results in Table 2 showed that Litchi exhibited the highest total phenolics content $(850.38$ $\mathrm{ug} / \mathrm{g})$, followed by Jackfruit (619.21 ug/g),Naseberry $(581.65 \mathrm{ug} / \mathrm{g})$, Longan $(162.98 \mathrm{ug} / \mathrm{g})$, Loquat(154.50 ug/g), while Carambola was the lowest at a level of $106.61 \mathrm{ug} / \mathrm{g}$. The sum of 
individual phenolic acids quantified by the HPLC analysis was not positively correlated the total phenolics content (Table 1). The reason could be explained that a lack of selectivity in the colorimetric Folin-Ciocalteu method, as well as interferences other compounds in the samples such as nitric compounds, saccharides.

Table 2. Bioactive compounds, retention time(RT),calibration curves and contents of six different leaf extracts

\begin{tabular}{|c|c|c|c|c|c|c|c|c|c|}
\hline Compounds & $\begin{array}{c}\mathrm{RT} \\
{[\mathrm{min}]}\end{array}$ & Calibration curves & $r^{2}$ & \multicolumn{6}{|c|}{ Contents[ug/g DW] } \\
\hline $\begin{array}{l}\text { Protocatechuic } \\
\text { acid }\end{array}$ & 7.09 & $\mathrm{Y}=5.835644 * 10^{-5} * \mathrm{X}-0.03226763$ & 0.9999 & -- & 1.53 & 0.93 & 1.12 & 14.15 & 22.16 \\
\hline $\begin{array}{l}\text { p-hydroxybenz } \\
\text { oic acid }\end{array}$ & 12.62 & $\begin{array}{l}\mathrm{Y}=6.043012 * 10-5 * \mathrm{X}-0.0076293 \\
94\end{array}$ & & -- & -- & 0.48 & 0.69 & -- & 0.80 \\
\hline $\begin{array}{l}\text { Chlorogenic } \\
\text { acid }\end{array}$ & 17.04 & $\mathrm{Y}=6.515556 * 10-5 * \mathrm{X}-0.112224$ & 0.9993 & 139.44 & 122.28 & 110.60 & -- & -- & -- \\
\hline Caffeic acid & 18.90 & $\mathrm{Y}=2.775624 * 10^{-5} * \mathrm{X}-0.01237511$ & 0.9999 & -- & 0.96 & 6.42 & 3.43 & -- & -- \\
\hline Vanillic acid & 20.53 & $\mathrm{Y}=5.58296 * 10^{-5} * \mathrm{X}+0.04986311$ & 0.9995 & -- & -- & 9.49 & 11.96 & 6.00 & 19.21 \\
\hline Epicatechin & 24.60 & $\mathrm{Y}=1.50774 * 10^{-4} * \mathrm{X}+0.07445303$ & 0.9993 & 35.00 & 2.81 & 9.06 & 18.03 & 31.74 & 86.45 \\
\hline Anthocyanin & 31.26 & $\mathrm{Y}=1.070547 * 10^{-4} * \mathrm{X}+0.2134273$ & 0.9995 & 2.19 & -- & 11.41 & 4.60 & -- & -- \\
\hline Cumaric acid & 32.31 & $\mathrm{Y}=2.011393 * 10^{-5 *} \mathrm{X}+0.01472338$ & 0.9997 & 0.60 & 0.64 & -- & 0.61 & -- & -- \\
\hline Ferulic acid & 39.96 & $\mathrm{Y}=2.468776 * 10^{-5 *} *-0.03098857$ & 0.9993 & 1.27 & $-{ }_{-}^{-0}$ & 0.22 & 0.98 & -- & -- \\
\hline Ellagic acid & 40.79 & $\mathrm{Y}=6.043461 * 10^{-5} * \mathrm{X}+0.6021855$ & 0.9944 & 363.19 & -- & -- & 8.81 & 97.40 & 178.2 \\
\hline Naringin & 46.19 & $\mathrm{Y}=7.120097 * 10^{-5} * \mathrm{X}+0.0015832$ & 0.9999 & -- & -- & 0.41 & 2.08 & -- & 4.08 \\
\hline Myricetin & 46.69 & $\mathrm{Y}=8.562619 * 10^{-5 *} * \mathrm{X}+0.2191827$ & 0.9998 & -- & 26.74 & -- & 33.58 & -- & -- \\
\hline Phloridzin & 47.41 & $\mathrm{Y}=5.629247 * 10^{-5} * \mathrm{X}-0.05442474$ & 0.9999 & -- & 0.75 & -- & -- & 1.97 & 2.91 \\
\hline Reseveratrol & 47.63 & $\mathrm{Y}=3.131901 * 10^{-5} * \mathrm{X}-0.01276966$ & 0.9999 & -- & -- & -- & -- & -- & -- \\
\hline Quercetin & 49.72 & $\mathrm{Y}=1.422701 * 10^{-5 *} * \mathrm{X}-0.02362044$ & 0.9999 & -- & -- & 0.08 & -- & -- & -- \\
\hline $\begin{array}{l}\text { Cinnamic acid } \\
\text { Total }\end{array}$ & 50.69 & $\mathrm{Y}=1.123543 * 10^{-5 *} \mathrm{X}-0.05574964$ & 0.9999 & 0.35 & 4.15 & 0.35 & -- & 2.92 & 0.61 \\
\hline $\begin{array}{l}\text { contents/ug/g } \\
\text { DW }\end{array}$ & & & & 581.65 & 619.21 & 154.50 & 106.61 & 162.98 & 850.38 \\
\hline
\end{tabular}

\subsection{Antioxidant capacity}

The free radical scavenging activity of each sample was determined by DPPH method (Table 3). The DPPH $\mathrm{IC}_{50}$ values varied from 0.06 to $0.19 \mathrm{mg} / \mathrm{mL}$. Naseberry had the lowest $\mathrm{IC}_{50}$ value, which represented the highest free radical scavenging capacity, followed by Carambola, Jackfruit, Longan and Litchi, while Loquat had the lowest scavenging activity. The radical scavenging capacity determined by ABTS method are showed in Table 3. ABTS $\left(\mathrm{IC}_{50}\right)$ values ranged from 1.87 to $26.39 \mathrm{ug} / \mathrm{mL}$. Their $\mathrm{IC}_{50}$ values from different samples in the order from high to low were trolox $>$ Loquat $>$ Litchi $>$ Longan $>$ Jackfruit $>$ Carambola $>$ Naseberry $>$ Vitamin C.

The ferric reducing antioxidant power (FRAP) assay was used to evaluate antioxidant capacities by reducing ferric iron to ferrous. As shown in Table 3, FRAP values varied from 0.324 to $2.49 \mathrm{mmol} \mathrm{FeSO}_{4} / \mathrm{g}$. FRAP value of Vitamin $\mathrm{C}$ was the highest, followed by Naseberry $(2.36$ $\mathrm{mmol} \mathrm{FeSO}_{4} / \mathrm{g}$ ), Carambola $\left(0.96 \mathrm{mmol} \mathrm{FeSO}_{4} / \mathrm{g}\right)$, Jackfruit $\left(0.93 \mathrm{mmol} \mathrm{FeSO}_{4} / \mathrm{g}\right)$, Longan $(0.90$ $\left.\mathrm{mmol} \mathrm{FeSO}_{4} / \mathrm{g}\right)$ and Litchi $\left(0.57 \mathrm{mmol} \mathrm{FeSO}_{4} / \mathrm{g}\right)$, while Loquat was the lowest. The metal chelating capacity of the extracts are shown in Table 3 and varied from 7.25 to $13.01 \%$. Their chelating capabilities in the order from high to low were Vitamin $\mathrm{C}>$ Litchi $>$ Carambola $>$ Longan $>$ Loquat $>$ Naseberry $>$ Jackfruit.

Table 3. Antioxidant activity of six different extracts(Mean \pm SD)

\begin{tabular}{ccccc}
\hline Samples & $\begin{array}{c}\mathrm{DPPH}\left(\mathrm{IC}_{50}\right) \\
{\left[\mathrm{mg} \cdot \mathrm{mL}^{-1}\right]}\end{array}$ & $\begin{array}{c}\mathrm{ABTS}\left(\mathrm{IC}_{50}\right) \\
{\left[\mathrm{ug} \cdot \mathrm{mL}^{-1}\right]}\end{array}$ & $\begin{array}{c}\text { FRAP } \\
{\left[\mathrm{mmol} \mathrm{FeSO}_{4} \cdot \mathrm{g}^{-1}\right]}\end{array}$ & $\mathrm{MCC}[\%]$ \\
\hline Naseberry & $0.06 \pm 0.001$ & $5.87 \pm 0.57$ & $2.36 \pm 0.02$ & $7.60 \pm 0.51$ \\
Jackfruit & $0.11 \pm 0.007$ & $13.03 \pm 1.03$ & $0.93 \pm 0.09$ & $7.25 \pm 0.0$ \\
Loquat & $0.19 \pm 0.02$ & $26.39 \pm 2.59$ & $0.53 \pm 0.02$ & $8.33 \pm 0.51$ \\
Carambola & $0.11 \pm 0.001$ & $11.40 \pm 1.47$ & $0.96 \pm 0.02$ & $9.06 \pm 0.51$ \\
Longan & $0.14 \pm 0.002$ & $16.22 \pm 0.98$ & $0.9 \pm 0.02$ & $8.33 \pm 0.51$ \\
Litchi & $0.17 \pm 0.012$ & $19.87 \pm 2.13$ & $0.57 \pm 0.0$ & $9.06 \pm 0.51$ \\
Vc & $0.01 \pm 0.00$ & $1.87 \pm 0.08$ & $2.49 \pm 0.02$ & $13.01 \pm 1.45$ \\
Trolox & 0.1480 & 25.634 & $0.324 \pm 0.00$ & -- \\
\hline
\end{tabular}

\section{Conclusion}

The six leaves selected in this study showed that Naseberry leaves extract was richer in phenolic acids and flavonoids than other leaves. Twenty-one phenolic compounds in six tropical 
fruits leaves were simultaneously quantified by the HPLC in this study. Rutin, ellagic acid, chlorogenic acid and salicylic acid were the main phenolic compounds in all types of leaves and contributed to the great antioxidant properties. The results of this study present the nutritional value of these waste plant leaves and provides their value-added utilization methods such as natural antioxidants food ingredients.

\section{Acknowledgements}

This work were financially supported by the Fund on Basic Scientific Research Project of Nonprofit Central Research Institutions(1630062015011), Agricultural Ecology Environmental Protection Project.

\section{References}

[1] M. D. Sokovic' , J.Vukojevic' , P. D.Marin, D. D. Brkic' , V.Vajs , L. J. L.D.Van Griensvon: Molecules. (2009) 14(1):238-249.

[2] S.Kanatt, R.Chander, A.Sharma: Food Chemistry. (2008)107:845-852.

[3] Y.Seun-Ah, S J.ang-Kyung, L.Eun-Jung, L. S. Chang-Hyun, L.In-Seon: Journal of Natural Product Research. (2010) 24(2):140-151.

[4] A.Amal, A.Ashraf: Journal of Biyoloji Bilimleri Arastirma Dergisi.(2009)2(2): 71-79.

[5] G.X.Jiang,S.Lin,L.R.Wen,Y.M.Jiang,M.M.Zhao,F.Chen,K.N.Prasad,X.W.Duan,B.Yang: Food Chemistry. (2013)136(2):563-568

[6] D.O.Kim, O. K.Chun, Y. J.Kim, H.Y.Moon, C. Y.Lee: Journal of Agricultural and Food Chemistry.(2003) 51(22): 6509-6515.

[7] C. M.Liyana-Pathirana, F.Shahidi:Journal of Agricultural and Food Chemistry. (2005) 53(7): 2433-2440.

[8] R.Re, N.Pellegrini, A.Proteggente, A.Pannala, M.Yang. C.Rice-Evans:Free Radical Biology and Medicine.(1999)26: 1231-1237.

[9] L.F.Benzie, Strain, J.J: Analytical Biochemistry. ( 1996)239:70-76.

[10]T.C.P.Dinis, V.M.C.Madeira, L.M.Almeida: Archives of Biochemistry and Biophysics, (1994) 315:161-169. 